\title{
Significance of Primary Melanoma Regression on Local Infiltrate and Outcome
}

\author{
Awatef Kelati ${ }^{1,2}$, Brigitte Balme ${ }^{3}$, Brigitte Chouvet $^{3}$, Alexandra Traverse-Glehen ${ }^{3}$, \\ Juliette Tantot ${ }^{3}$, Olivier Harou ${ }^{3}$, Gérard Duru ${ }^{4}$, Sebastien Debarbieux ${ }^{1}$, Stephane Dalle ${ }^{1,5,6}$, \\ Luc Thomas ${ }^{1,5,6}$
}

1 Dermatology Department, Hôpital Universitaire Lyon Sud, Hospices Civils de Lyon. Pierre-Bénite, France

2 Dermatology Department, Cheikh Khalifa International University Hospital, Mohammed VI University of Health Sciences (UM6SS), Casablanca, Morocco

3 Anatomo-Pathology Department, Hôpital Universitaire Lyon Sud, Hospices Civils de Lyon. Pierre-Bénite, France

4 Research director in the Claude Bernard University, Lyon, France

5 Lyon 1 University Lyon France

6 Lyon Cancer Research Center, Centre Léon Bérard Lyon France

Key words: primary melanoma, local infiltrate, outcome, histopathology, dermoscopy

Citation: Kelati A, Balme B, Chouvet B et al. Significance of primary melanoma regression on local infiltrate and outcome. Dermatol Pract Concept. 2022;12(1):e2022034. DOI: https://doi.org/10.5826/dpc.1201a34

Accepted: September 1, 2021; Published: January 2022

Copyright: $@ 2022$ Kelati et al. This is an open-access article distributed under the terms of the Creative Commons AttributionNonCommercial License (BY-NC-4.0), https://creativecommons.org/licenses/by-nc/4.0/, which permits unrestricted noncommercial use, distribution, and reproduction in any medium, provided the original authors and source are credited.

Funding: this work is supported in part by grants from Université Claude Bernard Lyon 1 (to LT and SD), from the Hospices Civils de Lyon (to LT and SD), from the association Vaincre le mélanome (to LT), from Melarnaud (to SD), from Lyrican (to SD), from the Fondation ARC (to SD).

Competing interests: None.

Authorship: All authors declare that they have sufficiently participated in the submitted work; all have had access to clinical material and have revised the manuscript before submission. Study concept and design: AK, BB, SD, and LT; Data acquisition, data analysis and interpretation, critical revision of the manuscript, and intellectual input: all authors; Drafting of manuscript: AK, BB, OH, SD, and LT; Statistical analysis: GD.

Corresponding author: Awatef Kelati, MD, Dermatology Department, Cheikh Khalifa International University Hospital, Mohammed VI University of Health Sciences (UM6SS), Casablanca, Morocco. E-mail: awatkelati@gmail.com

ABSTRACT Introduction: The characteristics and the prognostic value of regression in primary melanomas are controversial.

Objectives: To further characterize "hot" and "cold" tumor's stromas and to investigate the association between dermoscopy, pathology, and the prognostic implications of regression.

Methods: A 14-year-collection-based retrospective analysis was carried out on 40 patients with confirmed regressive melanomas.

Results: The extent of regression in dermoscopy was associated with the stage of the regression (P $=0.05)$ and with the MelanA patterns in histology $(\mathrm{P}=0.02)$. Blue-gray and gray-brown color of the peppering $(\mathrm{P}=0.01)$, and the eccentric, multifocal character of the dermoscopic regression $(\mathrm{P}=$ $0.05)$ were associated with "hot" stromas (CD8+, Granzym B+). Focal histologic regression (regressing melanomas) was associated with a good outcome $(\mathrm{P}<0.001)$, while a complete regression (regressed melanomas) was associated with melanoma-related death $(\mathrm{P}<0.001)$. "Hot" stromas $\left(\mathrm{CD} 8^{+}\right.$were 
significantly associated with survival at 10 years $(\mathrm{P}=0.044)$, while "hot" stromas (Granzyme $\left.\mathrm{B}^{+}\right)$were associated with the locoregional extension $(P=0.016)$, and the initial distant metastasis $(P=0.016)$.

Conclusions: Dermoscopic features of regression in primary melanomas were associated with the stage of regression, its extent, and the "hot" or "cold" nature of the tumor stroma, with prognostic implications.

\section{Introduction}

Histopathological features of regression, encountered in $10 \%-35 \%$ of primary cutaneous melanomas [1,2], classically appear on dermoscopy as white (or blue-white) scarlike areas (WSA) [3,4], variably admixed with blue-gray granularity (BGG) or "peppering”. Both WSA and BGG are unspecific features of regression, and are often regularly distributed on more than $50 \%$ of the surface benign lesions, while they are smaller and irregularly distributed in melanomas [3-6]. Recently, reticulated regression has been described in in situ or slow-growing invasive melanomas as a new dermoscopic feature of regression, and appears as a coarse blue-gray net, with thick gray-blue lines with large pink-colored holes [2,7]. Although classic histopathological features of primary melanoma regression have been described over the past decades, their clinical implications and prognostic value remain unclear and controversial [2,8-16].

New interest in the evaluation of the nature of the host response, and the subsequent regression features in malignant tumors, especially melanomas, came after the development of immunotherapy. Tumor stromas have been sub-classified into "hotly" and "coldly" infiltrated by immune cells [17], with the pathogenic hypothesis that "hot" tumors may respond better to immunotherapy, which stimulates the already present immune cells, whereas "cold" tumors should (or could) be initially stimulated by specific neo-adjuvant agents before the initiation of immunotherapy.

\section{Objectives}

The primary aim of the present study was to further characterize "hot" and "cold" stromas in regressive melanomas based on dermoscopic and histopathologic criteria, and to preoperatively analyze dermoscopic features at different stages of regression. The secondary aim was to investigate the association between dermoscopy, pathology, and the prognostic implications of regression, with the ultimate goal of helping in the pre-therapeutic definition of "hot" tumors, which may benefit from postoperative adjuvant immunotherapy, and "cold" tumors, which could be included in potential neo-adjuvant clinical trials in priority before the excision of the primary tumor.

\section{Methods}

The present study was approved by the Hospices Civils de Lyon ethics committee, project $\mathrm{N}^{\circ} 20-15$ (2019). It is a collection-based retrospective study of a consecutive series of patients having cutaneous melanomas with both confirmed dermoscopic and histopathological changes of regression, over a period of 14 years (2006-2019), for whom a complete set of clinical dermoscopic photographs was available. All patients gave their written informed consent for the use of their clinical records, clinical and dermoscopic images, pathological specimen at the time of the primary excision of the tumor, and subsequent inclusion in the Centre de Ressources Biologiques (Institutional biobank) of the Hospices Civils de Lyon for research purposes.

This study has not been registered in a public trial registry because it does not prospectively assigns human subjects to intervention or comparison groups to evaluate the cause and effect relationship between a medical intervention and a health outcome. This study does not fall into the scope of the French Jardé law, of $16^{\text {th }}$ November 2016 because it uses a preexisting cohort of patients and preexisting clinical records.

The exclusion criteria were the absence or the poor quality of the dermoscopic images and the non-confirmation of the presence of histopathological features of regression upon reevaluation of the original histopathological slides. Clinical history, clinical and dermoscopic images, histopathological reports, standard immunochemistry data (MelanA), and, when applicable, genotyping of BRAF mutations were directly collected from patient electronic records.

Dermoscopic images were analyzed by 3 independent experienced dermoscopists. Regression-associated features were recorded as well (WSA and BGG), and were specifically evaluated for their presence, their disposition (central, eccentric, unifocal, multifocal), and their surface extension (on less than $25 \%$, between $25 \%$ and $50 \%$, or on more than $50 \%$ of the lesion). The presence or absence of reticular regression was also recorded.

Histopathological and MelanA slides were evaluated independently by 4 dermatopathologists with no knowledge of the original histopathology report; the regression was sub-classified into 3 stages as reported in the literature [2]. Stage 1, or "inflammatory phase", is characterized by a still recognizable tumor, with dense lymphocytic infiltrates admixed with nests of malignant melanocytes. Stage 2 or "regressing phase" is characterized by still recognizable 
melanoma cells, with tumor reduction or disappearance in the overlying epidermis, while in the papillary dermis the malignant tissue is replaced by lymphocytes and fibrosis. An increased vascularity is also observed because of angiogenesis, and heavily pigmented macrophages can be observed. Stage 3 or "regressed melanoma" is characterized by the complete disappearance of the tumor that is replaced by a dense fibrotic tissue with vessels and melanophages in varying numbers, with few or no lymphocytes underneath a thinned epidermis. The extent of regression was also examined, and classified as focal if it involved a portion of the dermal component of the tumor, partial if it involved the entire dermal component, and complete if it involved the entire tumor [2].

Additional immunophenotypic studies (CD8, Langerin, Granzyme B, and PDL-1) and an Orcein stain were performed on formalin-fixed paraffin-embedded original pathological specimens. The proportion (\%) of cells positive for CD8, Granzyme B, Langerin, and PDL-1 was evaluated in the area of the regression and in the tumor stroma, and categorized as covering $<5 \%, \geqslant 5$ and $<10 \%, \geqslant 10$ and $<25 \%, \geqslant 25$ and $<$ $50 \%, \geqslant 50$ and $>75 \%$, or $>75 \%$ of the whole inflammatory infiltrate. After discussion between the authors and a review of all the slides, tumors were considered as "hot" if their stroma was $\mathrm{CD} 8{ }^{+}$on more than $25 \%$, Granzyme $\mathrm{B}^{+}$on more than $10 \%$ of the inflammatory infiltrate, PDL- $1^{+}$on more than $5 \%$, or Langerin ${ }^{+}$on more than $5 \%$. Otherwise, they were considered as "cold".

Following our clinical practice, BRAF mutation was tested only for primary tumors thicker than $1.00 \mathrm{~mm}$.

\section{Statistical Analysis}

Analyses were performed using the Statistical Package for the Social Studies software version 20. Quantitative variables were expressed as mean ( \pm standard deviation, SD) and qualitative variables as count (percentage). Progression-free survival was defined as the number of months from the diagnosis to the identification of locally recurrent or metastatic disease in the lymph nodes or distant organs. Death was considered as melanoma-related in patients for whom the melanoma had progressed. A univariate analysis was performed to investigate the association between histological regression characteristics, inflammatory infiltrate status, and prognosis, using a chisquared $^{2}$ test. A P value $\leqslant 0.05$ was considered as significant.

\section{Results}

Among the 98 patients from the collection database, only 40 were included ( 30 were excluded because of incomplete dermoscopy record, 28 were excluded because of the absence of clear-cut histopathological features of regression). The mean (SD) age of included patients was 63.6 (15.7) years, and $82.5 \%$ of them presented with melanomas in the local stage (I and II of the AJCC 2018 Melanoma staging; Table 1).

Within the regression area of the tumor, WSA were observed in $55 \%$ of lesions, blue-WSA in $45 \%$, BGG in $97.5 \%$ (Figures 1-3). Reticular regression was observed in $75 \%$ of cases, and was associated with the polychromatic character of the lesion $(\mathrm{P}=0.047)$ and the stage 2 of the regression in histology $(\mathrm{P}=0.049)$.

Table 1. Descriptive Analysis of Patients Included in the Present Study

\begin{tabular}{|l|c|}
\multicolumn{1}{|c|}{ Total population $\mathbf{n}=\mathbf{4 0}$} & $\mathbf{N}(\%)$ \\
\hline Mean age, years (SD) & $24.6(15,7)$ \\
\hline Sex, male & $6(15)$ \\
\hline Lymph node metastasis & $6(15)$ \\
\hline Metastatic melanoma & \\
\hline Dermoscopic regression variables & $18(45)$ \\
\hline Blue-white areas & $22(55)$ \\
\hline Blue-white & $2(5)$ \\
White & $37(92,5)$ \\
\hline Blue -white areas characteristics & $14(35)$ \\
\hline Central & $10(25)$ \\
Eccentric & $16(40)$ \\
\hline Coverage of the lesion & $39(97,5)$ \\
\hline Less than 25\% & $37(92,5)$ \\
\hline $25-50 \%$ & $2(5)$ \\
\hline More than 50\% & \\
\hline Peppering & \\
\hline Focal & \\
Total & \\
\hline
\end{tabular}


Table 1. Descriptive Analysis of Patients Included in the Present Study (continued)

\begin{tabular}{|c|c|}
\hline Total population $n=40$ & $\mathbf{N}(\%)$ \\
\hline \multicolumn{2}{|l|}{ Color of the lesion } \\
\hline $\begin{array}{l}\text { Brown-gray } \\
\text { Grey-blue } \\
\text { Grey-blue and brown-gray }\end{array}$ & $\begin{array}{l}13(32.5) \\
14(35) \\
12(30)\end{array}$ \\
\hline Reticular regression in less palpable area & $30(75)$ \\
\hline $\begin{array}{l}\text { Grey-blue lines } \\
\text { Brown-gray lines }\end{array}$ & $\begin{array}{l}20(50) \\
10(25)\end{array}$ \\
\hline \multicolumn{2}{|l|}{ Vascularization } \\
\hline $\begin{array}{l}\text { Polymorphic vessels } \\
\text { Linear irregular }\end{array}$ & $\begin{array}{c}25(62.5) \\
2(5)\end{array}$ \\
\hline \multicolumn{2}{|l|}{ Histopathology and immunochemistry } \\
\hline $\begin{array}{l}\text { Melanoma histological subtype } \\
\text { SSM } \\
\text { Regressive unclassifiable } \\
\text { LM } \\
\text { ALM }\end{array}$ & $\begin{array}{c}25(62.5) \\
7(17.5) \\
6(15) \\
2(5) \\
\end{array}$ \\
\hline $\begin{array}{l}\text { Stage of the regression } \\
1 \\
2 \\
3\end{array}$ & $\begin{array}{c}3(7.5) \\
24(60) \\
13(32.5)\end{array}$ \\
\hline $\begin{array}{l}\text { Extent of regression } \\
\text { Complete } \\
\text { Focal } \\
\text { Partial }\end{array}$ & $\begin{aligned} 1 & (2.5) \\
27 & (67.5) \\
12 & (30)\end{aligned}$ \\
\hline $\begin{array}{l}\text { MelanA } \\
\text { Normal (stage } 1 \text { of regression) } \\
\text { Reduced in the dermis, reduced in the epidermis } \\
\text { Absent in the dermis, reduced in the epidermis }\end{array}$ & $\begin{array}{c}1(2.5) \\
26(65) \\
13(32.5)\end{array}$ \\
\hline $\begin{array}{l}\text { Orcein in the regression area } \\
\text { Repressed, condensed, horizontal } \\
\text { Repressed, not condensed, horizontal }\end{array}$ & $\begin{array}{c}35(87.5) \\
5(12.5) \\
\end{array}$ \\
\hline Immunochemistry (Hot stromas) & \\
\hline $\begin{array}{l}\text { CD8+ } \\
\text { Granzyme B+ } \\
\text { Langerin }+ \\
\text { PDL1+ }\end{array}$ & $\begin{array}{l}37(92.5) \\
22(55) \\
21(52.5) \\
14(35)\end{array}$ \\
\hline Mutation BRAF V600 E & $5(12.5)$ \\
\hline $\begin{array}{l}\text { Melanoma staging AJCC } 2018 \\
\text { I and II (local) } \\
\text { III (loco-regional) } \\
\text { IV (Metastatic) }\end{array}$ & $\begin{array}{c}33(82.5) \\
2(5) \\
5(12.5) \\
\end{array}$ \\
\hline $\begin{array}{l}\text { Evolution after } 2 \text { years of treatment } \\
\text { Death } \\
\text { Stable without clinical or radiologic evolution } \\
\text { Complete remission after more than } 2 \text { years }\end{array}$ & $\begin{array}{c}2(5) \\
6(15) \\
30(75)\end{array}$ \\
\hline
\end{tabular}

SSM=Superficial spreading melanoma

LM: Lentigo maligna

ALM=Acral lentiginous melanoma

$\mathrm{AJCC}=$ American Joint Committee on Cancer 


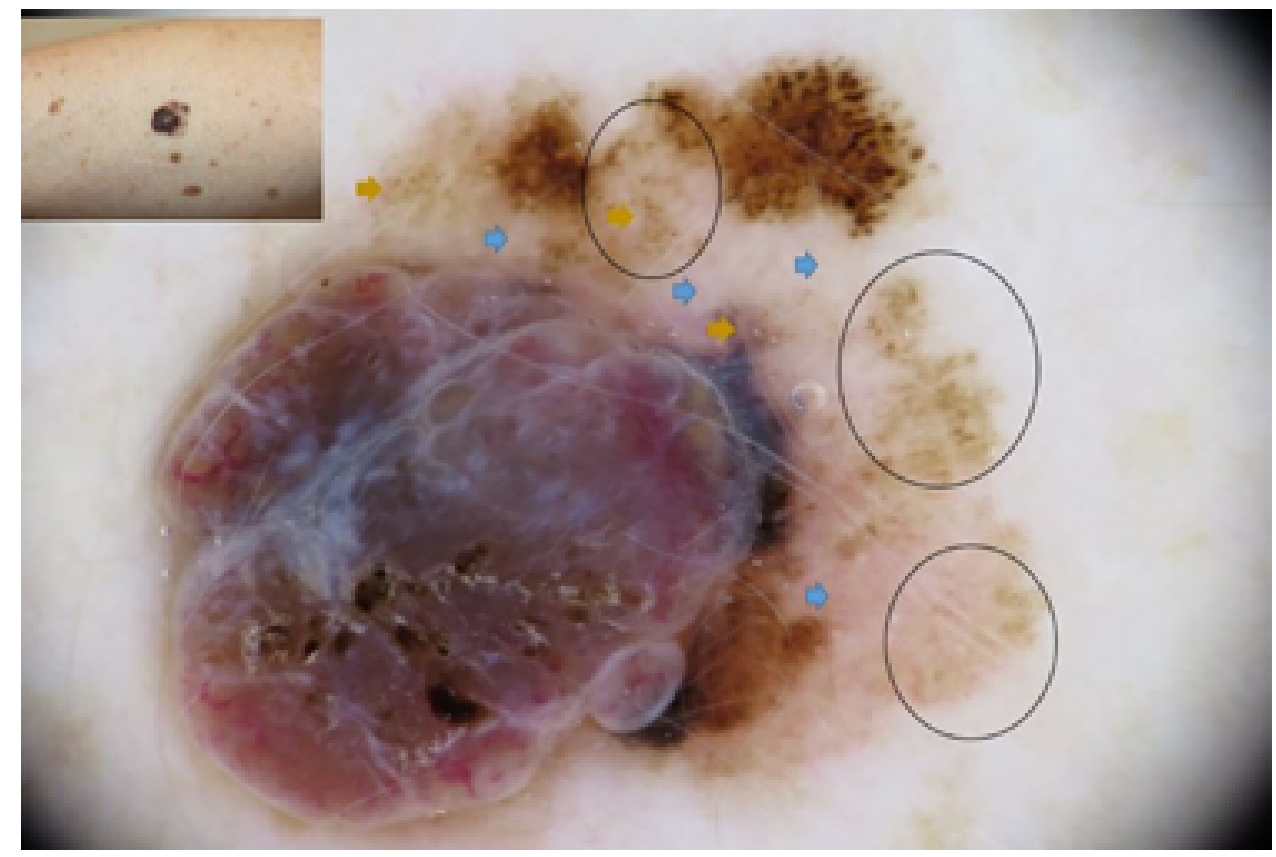

Figure 1. Clinical and dermoscopic images of a regressing melanoma. Multicomponent pattern with multiple peripheral eccentric white scar-like areas (blue arrow) covering less than $50 \%$ of the lesion, with reticular regression (black circle). Focal peppering (brown arrow).

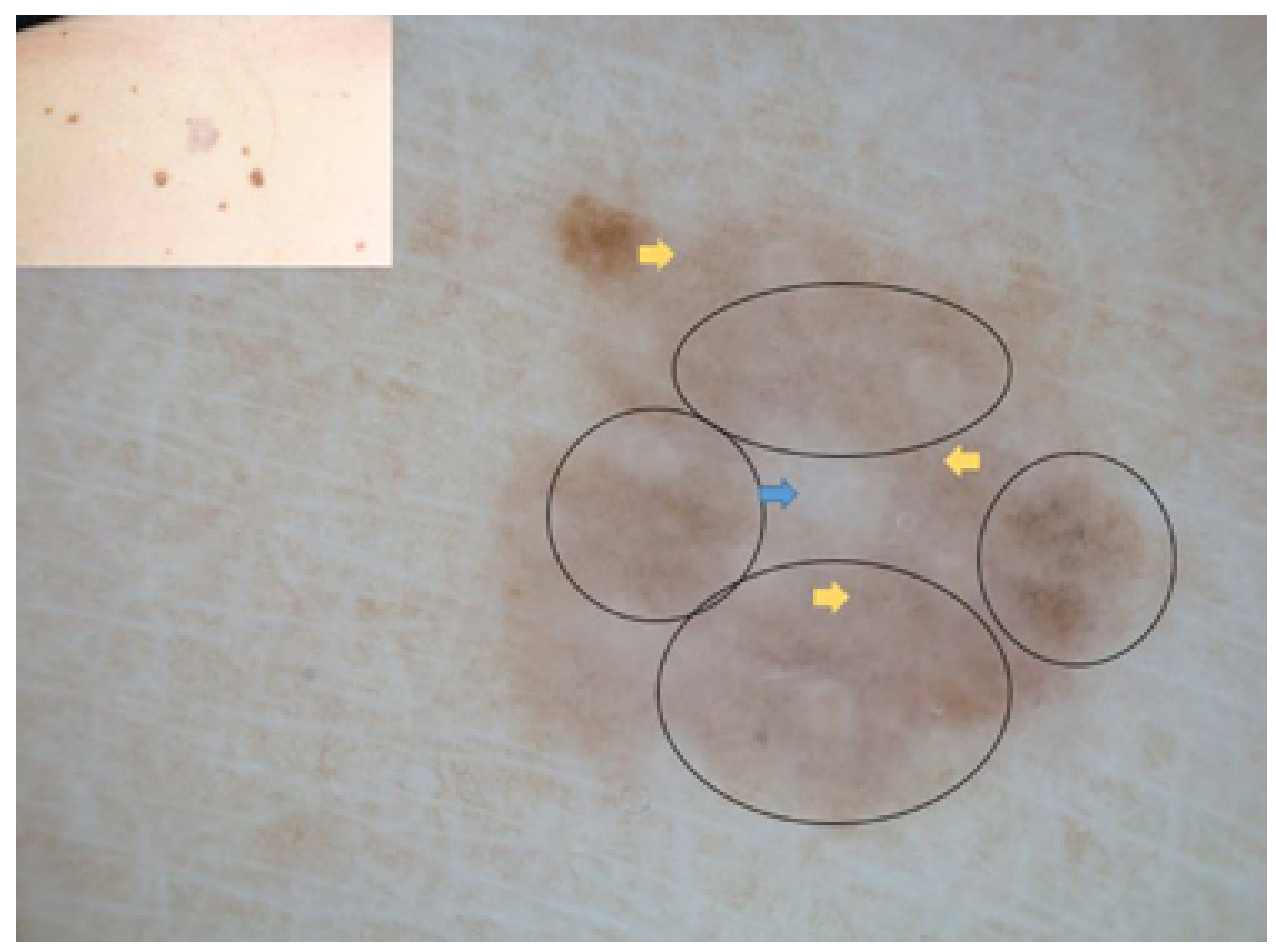

Figure 2. Clinical and dermoscopic images of a regressed melanoma. White-blue scar-like areas (blue arrow), and extensive peppering (brown arrow) covering more than $75 \%$ of the lesion, with reticular regression (black circles).

Peppering was associated with thin melanomas $(<1 \mathrm{~mm}, \mathrm{P}$ $=0.012)$ and positive BRAF mutations $(\mathrm{P}=0.028)$. WSA were associated with follicular migration in histology $(\mathrm{P}=0.014)$. The extent of regression in dermoscopy was associated with the stage of regression $(\mathrm{P}=0.05)$ and to MelanA patterns in histology $(\mathrm{P}=0.023)$. Chaotic lesions were associated with stage 1 and 2 of regression $(P=0.035)$, irregular thick reticular lines $(P=0.049)$ and blue white veil $(P=0.014)$ were associated with stage 2 of regression. Annular granular pattern was associated with stage 2 and 3 of regression $(\mathrm{P}=$ 0.009). Skin fissures exaggeration in dermoscopy $(\mathrm{P}<0.001)$, the presence of eccentric globules $(P=0.027)$, blue-white area 


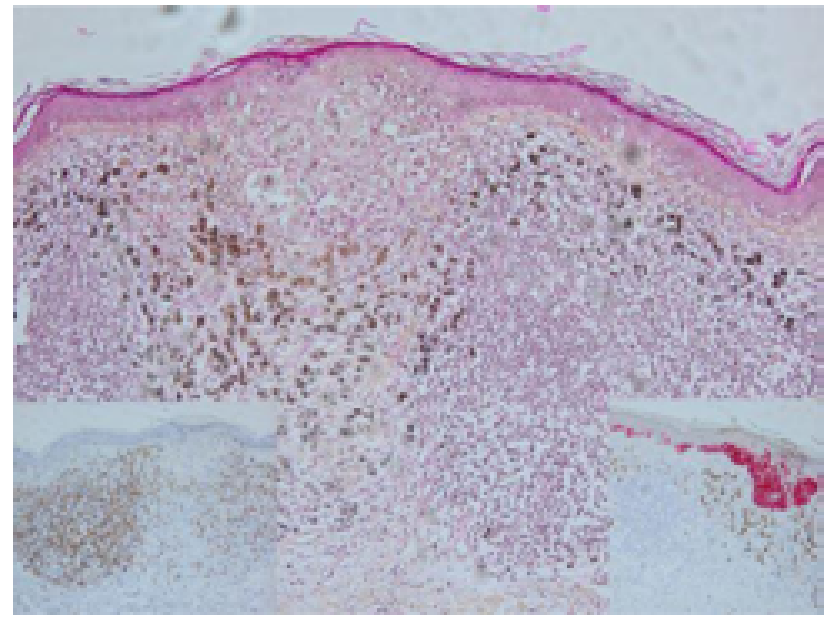

Figure 3. Hot stroma in a regressive melanoma. Stage 2 of histologic regression with the corresponding melanA pattern as reduced in the dermis and reduced in the epidermis, and CD8+ immunochemistry on more than $50 \%$ of the inflammatory infiltrate (magnification $\mathrm{x} 10$ ). veil $(P=0.038)$, and perifollicular circles $(P=0.045)$ were associated with focal regression in histology. The loss of normal elastic fiber architecture in Orcein stain was associated with the WSA with peppering $(\mathrm{P}=0.001$; Table 2$)$.

On the other hand, red milky areas $(\mathrm{P}=0.033)$, irregular thick reticular lines $(\mathrm{P}=0.044)$, polygones $(\mathrm{P}=0.044)$, and blue-gray and gray-brown color of the peppering granules $(\mathrm{P}=0.011)$ were associated with "hot" Granzyme B+ tumors, while "hot" $\mathrm{CD} 8^{+}$stromas were associated with skin fissures exaggeration $(\mathrm{P}=0.043)$ and with the eccentric and multifocal character of regression in dermoscopy $(\mathrm{P}=$ 0.05). "Cold" PDL1+ stromas were associated with inversed network in dermoscopy $(\mathrm{P}=0.05)$ and eccentric globules $(\mathrm{P}$ $=0.044)$, while "cold" Langerin ${ }^{+}$stromas were associated with the multicomponent pattern $(\mathrm{P}=0.032)$, peripheral structureless area $(\mathrm{P}=0.026)$, and the rhomboidal pattern $(\mathrm{P}=0.049)$ (Table 2).

Table 2. Univariate Analysis

\begin{tabular}{|c|c|c|}
\hline \multicolumn{2}{|c|}{ Variables } & \multirow{2}{*}{$\begin{array}{l}\text { P value } \\
0,000\end{array}$} \\
\hline Immunodepression & Stage 3 of regression & \\
\hline Elevated lesion (plaque ou nodular) & Hot stroma Granzyme B+ & 0,038 \\
\hline \multirow[t]{3}{*}{ Lesion color (polychromatic or achromic) } & BRAF mutation & 0,035 \\
\hline & Regression extent & 0,041 \\
\hline & $\begin{array}{l}\text { Reticular regression in an area les palpable than the } \\
\text { other areas }\end{array}$ & 0,014 \\
\hline \multirow[t]{3}{*}{ Loco-regional metastasis } & Dermoscopic regression (Blue-white areas (scar like)) & 0,041 \\
\hline & Focal regression in histology & 0,004 \\
\hline & Hot stroma Granzym B + & 0,016 \\
\hline \multirow[t]{2}{*}{ Peppering } & Focal regression (focal peppering) & 0,000 \\
\hline & $\begin{array}{l}\text { Low risk of recurrence after complete remission after } \\
\text { surgery }\end{array}$ & 0.029 \\
\hline \multirow[t]{2}{*}{ Extent of regression in dermoscopy } & MelanA expression & 0,023 \\
\hline & Regression stages in histology & 0,05 \\
\hline \multirow[t]{2}{*}{ Eccentric character of regression in dermoscopy } & Stage 2 and 3 & 0,012 \\
\hline & Hot stroma CD8 + & 0,05 \\
\hline Granules color & Hot stroma Granzym B + & 0,011 \\
\hline Reticular type of regression & Regression stage 2 & 0,049 \\
\hline \multirow[t]{2}{*}{ Annular granular pattern } & Stage 2 and 3 of regression & 0,009 \\
\hline & $\begin{array}{l}\text { Good outcome with complete remission, and no } \\
\text { evolution after treatment }\end{array}$ & 0.001 \\
\hline \multirow[t]{2}{*}{ Irregular thick reticular lines } & Stage 2 of regression & 0,049 \\
\hline & Hot stroma Granzyme B + & 0,044 \\
\hline \multirow[t]{4}{*}{ Skin fissures exaggeration } & Focal regression in histology & 0,000 \\
\hline & Hot stroma CD8 + & 0,043 \\
\hline & $\begin{array}{l}\text { Good outcome with complete remission, and no } \\
\text { evolution after treatment }\end{array}$ & 0.002 \\
\hline & Good response to immunotherapy & 0.003 \\
\hline
\end{tabular}


Table 2. Univariate Analysis (continued)

\begin{tabular}{|c|c|c|c|}
\hline \multicolumn{3}{|c|}{ Variables } & $P$ value \\
\hline \multirow[t]{3}{*}{ Blue-white area (veil) } & \multicolumn{2}{|c|}{$\begin{array}{l}\text { MelanA pattern: reduced in the dermis, reduced or } \\
\text { normal in the epidermis }\end{array}$} & 0,010 \\
\hline & \multicolumn{2}{|c|}{ Stage 2 of regression } & 0,014 \\
\hline & \multicolumn{2}{|c|}{ Focal regression in histology } & 0,038 \\
\hline Pseudopods & \multicolumn{2}{|c|}{$\begin{array}{l}\text { Good outcome with Complete remission, and no } \\
\text { evolution after treatment }\end{array}$} & 0.033 \\
\hline Peripheral focal irregular network & \multicolumn{2}{|c|}{$\begin{array}{l}\text { Good outcome with a complete remission, and no } \\
\text { evolution after treatment }\end{array}$} & 0.05 \\
\hline Polygones & \multicolumn{2}{|c|}{ Hot stroma Granzym B+ } & 0,044 \\
\hline \multirow[t]{2}{*}{ Melanoma stage (AJCC 2018) } & \multicolumn{2}{|c|}{ The extent of regression } & 0.01 \\
\hline & \multicolumn{2}{|c|}{ Hot stroma CD8+ } & 0.038 \\
\hline \multirow[t]{2}{*}{ Regression stage } & Stage 2 & local extension & 0.030 \\
\hline & Stage 3 & $\begin{array}{l}\text { melanoma specific death (at } 2 \text { years, } 5 \\
\text { years of initial treatment) }\end{array}$ & $\begin{array}{l}\mathrm{p}=0.048 / \\
\mathrm{p}=0.020\end{array}$ \\
\hline Immunotherapy response & \multicolumn{2}{|c|}{ Hot stroma CD $8+$} & 0.032 \\
\hline \multirow[t]{2}{*}{ Progression free survival } & \multicolumn{2}{|c|}{ Regression extent } & 0.005 \\
\hline & \multicolumn{2}{|c|}{ Hot stroma CD8+ } & 0.044 \\
\hline Melanoma specific death & \multicolumn{2}{|c|}{ Regression extent } & 0.000 \\
\hline
\end{tabular}

Focal regression was associated with good outcome $(\mathrm{P}<$ $0.001)$ and the immunotherapy response $(\mathrm{P}<0.001)$, while complete and partial regression of histology were associated with melanoma-related death $(\mathrm{P}<0.001)$, regression stage 3 of histology was associated with melanoma-related death at both 2 years $(P=0.048)$ and 5 years $(P=0.020)$ since initial treatment. "Hot" CD8 ${ }^{+}$stromas were associated with a good response to immunotherapy $(\mathrm{P}=0.032)$, and with the survival at 10 years $(\mathrm{P}=0.044)$. Also, "hot" Granzyme $\mathrm{B}^{+}$stromas were associated with locoregionnal extension $(\mathrm{P}=0.016)$, and initial distant metastasis $(\mathrm{p}=0.016)$ (Table 2$)$.

The local extension (in transit metastasis) of these regressive melanomas was associated with the stage 2 of regression $(\mathrm{P}=$ 0.030), while locoregional extension and initially distant metastasis were associated with WSA in dermoscopy $(\mathrm{P}=0.041)$ and with focal regression in histology $(\mathrm{P}=0.008$; Table 2).

\section{Conclusions}

In the present study we were able to further characterize "hot" and "cold" stromas in the context of melanoma regression based on dermoscopic criterias and the inflammatory infiltrate status. Indeed, we found an association of many and specific dermoscopic features with "hot" Granzyme B+ and "hot" CD8 ${ }^{+}$stromas, or "cold" PDL1 $1^{+}$and "cold" Langerin ${ }^{+}$stromas. This further characterization of the previous sub-classification of "hot" and "cold" stromas in melanomas [17] based on the immunopathology nature of the inflammatory infiltrate had interesting prognostic implications, as $\mathrm{CD} 8^{+}$ stromas were significantly associated with a good response to immunotherapy, and to the disease free survival at 10 years, which confirms a study that has previously reported an association between CD8 T-cell infiltration and better prognosis [14]. Also, "hot" Granzyme B ${ }^{+}$stromas were associated with locoregional extension and the initial distant metastasis, while no prognostic implication of Langerin or PDL-1 expression around the tumor and in the regression were found in the present study. The prognostic value of PDL-1 is controversial, as some authors have failed to observe a correlation between PDL-1 expression in sentinel lymph node metastases and the outcome (which is consistent with our results), while others have reported PDL-1 as an independent negative prognostic marker in conventional melanoma, and, in contrast, others have reported PDL-1 expression in mucosal melanomas as correlated with longer recurrence-free survival [18].

A preoperatively comparison of various dermoscopic features of regressive melanoma at different stages of regression was made, and the association between dermoscopy, pathology, and the prognostic implications of regression was investigated. Peppering was found as significantly associated with thin melanomas in histology, this refines knowledge about peppering that has been described as an expression of melanophages in the dermis [2], and has been significantly associated with BRAF mutation [2], confirming that regression may be a hallmark of BRAFV600 melanomas. In addition, in primary melanomas, mutated BRAF has been 
described as an adverse prognostic factor [20]. In the present study, even though BRAF mutation status was not found in many patient records because most had thin melanomas, it was significantly associated to rapidly growing melanomas, which were polychromatic, chaotic, or with a multicomponent pattern in dermoscopy, or with signs of horizontal growth and local extension. As a result, BRAF mutation may be a prognostic factor in regressive melanomas. Also, the dermoscopic extent of regression (WSA with peppering) was significantly associated with regression stages in histology and enabled us to evaluate the aggressiveness of the tumor, since the results presented herein demonstrated an association between advanced stages of regressive melanomas and the extent of regression, and between stage III melanoma and melanoma-related death. In addition, the presence of dermoscopic signs associated with hot stromas CD8+ or Granzyme B + ( rRed milky areas, irregular thick reticular lines, polygones, the peppering granules' color, and the eccentric, multifocal character of regression), supports the idea that further dermoscopic investigations of the regression in primary melanomas would be of great help in the pre-excision therapeutic evaluation and predictable therapeutic response.

Reticular regression in a clinically less palpable area, which has been recently reported [7,19], was frequent in patients who had stage 2 of regression in thin melanomas. This type of regression may be correlated with the remaining junctional component and the heterogeneous dermal regression in stage 2 before the complete disappearance of the dermal tumor.

Remarkably, MelanA red immunostaining could be a good tool to confirm, characterize, and probably classify the histologic regression, especially when histologic regression is not so obvious. Despite contradictions in the literature, patients with thin melanomas who show partial regression cannot be included in the "low-risk" group if the extent of regression is more than 50\% [16,21,22]. Completely regressive lesions represent a factor of delay in diagnosis, and of development of locoregional and distant metastasis, as it has been reported in some case reports and studies [21,23]. This was also confirmed with the results herein as melanoma-related death was associated with regressed melanomas (stage 3 and complete regression).

The data herein suggest that the prognostic role of regression depends on the stage of melanoma, the stage of regression and its extent (regressing or regressed melanomas), and the "hot" or "cold" nature of the $\mathrm{CD}^{+}$and Granzyme $\mathrm{B}^{+}$ tumor stroma, which may explain the controversies found in the literature concerning regression [2] as it has not been precisely sub-classified previously.

Due to the retrospective nature of this study, many important data were missing from the patient records: for example, the BRAF status that was not determined for all patients, especially because most melanomas were thin, it was therefore not possible to draw conclusions about the prognostic value of BRAF mutation in regressive melanomas. However, even though this aspect would have been interesting to determine, and for future studies, it was not among our main objectives. Also, the small number of patients was due to the retrospective collection of the records and to the dermoscopic images themselves that were often not found or of poor quality, leading to the exclusion of some patient. Additionally, some patients were excluded after review by experienced pathologists because regression was not objectively observed.

The present study provides a better characterization of regression in primary melanomas, and a better comprehension of the "hot" or "cold" character of the stroma. An important outcome of the study is that regressing melanoma (early stages of regression) is associated with favorable outcome whereas regressed melanoma (complete regression stage 3 ) is associated with a worse outcome. Further studies with a prospective design could help in confirming and investigating these results, especially the importance of dermoscopy in predicting the immunophenotypic host response, with the ultimate goal to help in the pre-therapeutic definition of "hot" tumors that may benefit of postoperative adjuvant immunotherapy, and "cold" tumors in which inclusion in potential neo-adjuvant clinical trials could be proposed in priority before excision of the primary tumor.

\section{Acknowledgments}

We are grateful to Hélène Boyer and Philip Robinson (Direction de la Recherche Clinique et de l'Innovation, Hospices Civils de Lyon) for their help to improve the manuscript.

We would like also to thank Garance Tondeur from the research unity of the department of Dermatopathology for her help in obtaining consent from patients and in performing the immunochemistry analysis.

\section{References}

1. Blessing K, McLaren KM, McLean A, Davidson P. Thin malignant melanomas (less than $1.5 \mathrm{~mm}$ ) with metastasis: a histological study and survival analysis. Histopathology. 1990;17(5):389-395. DOI: 10.1111/j.1365-2559.1990.tb00757.x. PMID: 2076865.

2. Ribero S, Moscarella E, Ferrara G, Piana S, Argenziano G, Longo C. Regression in cutaneous melanoma: a comprehensive review from diagnosis to prognosis. J Eur Acad Dermatol Venereol. 2016;30(12):2030-2037. DOI: 10.1111/jdv.13815. PMID: 27401335.

3. Pastar Z, Lipozencić J, Rados J, Stajminger G. Regressing seborrheic keratosis - clinically and dermoscopically mimicking a regressing melanoma. Acta Dermatovenerol Croat. 2007;15(1):2426. PMID: 17433176.

4. Zaballos P, Blazquez S, Puig S, et al. Dermoscopic pattern of intermediate stage in seborrhoeic keratosis regressing to lichenoid 
keratosis: report of 24 cases. Br J Dermatol. 2007;157(2):266272. DOI: 10.1111/j.1365-2133.2007.07963.x. PMID: 17553042 .

5. Zalaudek I, Argenziano G, Ferrara G, et al. Clinically equivocal melanocytic skin lesions with features of regression: a dermoscopic-pathological study. Br J Dermatol. 2004;150(1):64-71. DOI: 10.1111/j.1365-2133.2004.05657.x. PMID: 14746618.

6. Stoecker WV, Wronkiewiecz M, Chowdhury R, et al. Detection of granularity in dermoscopy images of malignant melanoma using color and texture features. Comput Med Imaging Graph. 2011;35(2):144-147. DOI: 10.1016/j. compmedimag.2010.09.005. PMID: 21036538. PMCID: PMC3159567.

7. Seidenari S, Ferrari C, Borsari S, et al. Reticular grey-blue areas of regression as a dermoscopic marker of melanoma in situ. J Dermatol. 2010;163(2):302-309. DOI: 10.1111/j.13652133.2010.09821.x. PMID: 20426776.

8. Ronan SG, Eng AM, Briele HA, Shioura NN, Das Gupta TK. Thin malignant melanomas with regression and metastases. Arch Dermatol. 1987;123(10):1326-3130. PMID: 3662564.

9. Guitart J, Lowe L, Piepkorn M, et al. Histological characteristics of metastasizing thin melanomas: a case-control study of 43 cases. Arch Dermatol. 2002138(5):603-608. DOI: 10.1001/ archderm.138.5.603. PMID: 12020220.

10. Clark WH, Elder DE, Guerry D, et al. Model predicting survival in stage I melanoma based on tumor progression. J Natl Cancer Inst. 1989;81(24):1893-1904. DOI: 10.1093/jnci/81.24.1893. PMID: 2593166.

11. McCarthy WH, Shaw HM, McCarthy SW, Rivers JK, Thompson JF. Cutaneous melanomas that defy conventional prognostic indicators. Semin Oncol.1996;23(6):709-713. PMID: 8970591.

12. Cooper PH, Wanebo HJ, Hagar RW. Regression in thin malignant melanoma. Microscopic diagnosis and prognostic importance. Arch Dermatol. 1985;121(9):1127-1131. PMID: 4037837.

13. Trau H, Kopf AW, Rigel DS, et al. Regression in malignant melanoma. J Am Acad Dermatol. 1983;8(3):363-368. DOI: 10.1016/ s0190-9622(83)70040-x. PMID: 6833536.

14. McGovern VJ, Shaw HM, Milton GW. Prognosis in patients with thin malignant melanoma: influence of regression. Histopa- thology. 1983;7(5):673-680. DOI: 10.1111/j.1365-2559.1983. tb02279.x. PMID: 6629343.

15. Søndergaard K, Hou-Jensen K. Partial regression in thin primary cutaneous malignant melanomas clinical stage I. A study of 486 cases. Virchows Arch A Pathol Anat Histopathol. 1985;408(2-3):241-247. DOI: 10.1007/BF00707986. PMID: 3936263.

16. Kamino H, Tam S, Roses D, Toussaint S. Elastic fiber pattern in regressing melanoma: a histochemical and immunohistochemical study. J Cutan Pathol. 2010;37(7):723-729. DOI: 10.1111/j.16000560.2010.01531.x. PMID: 20184666.

17. Guillebon ED, Dardenne A, Saldmann A, et al. Beyond the concept of cold and hot tumors for the development of novel predictive biomarkers and the rational design of immunotherapy combination. Int J Cancer. 2020;147(6):1509-1518. DOI: 10.1002/ ijc.32889. PMID: 31997345.

18. Kraft S, Fernandez-Figueras M-T, Richarz NA, Flaherty KT, Hoang MP. PDL1 expression in desmoplastic melanoma is associated with tumor aggressiveness and progression. J Am Acad Dermatol. 2017;77(3):534-542. DOI: 10.1016/j.jaad.2017.05.007. PMID: 28728868.

19. Bassoli S, Borsari S, Ferrari C, et al. Grey-Blue Regression in Melanoma In Situ-Evaluation on 111 Cases. J Skin Cancer. 2011;2011:180980. DOI: 10.1155/2011/180980. PMID: 21748024; PMCID: PMC3118612.

20. Spathis A, Katoulis AC, Damaskou V, et al. BRAF Mutation Status in Primary, Recurrent, and Metastatic Malignant Melanoma and Its Relation to Histopathological Parameters. Dermatol Pract Concept. 2019;9(1):54-62. DOI: 10.5826/dpc.0901a13. PMID: 30775150. PMCID: PMC6368075.

21. Maurichi A, Miceli R, Camerini T, et al. Prediction of survival in patients with thin melanoma: results from a multi-institution study. J Clin Oncol. 2014;32(23):2479-2485. DOI: 10.1200/ JCO.2013.54.2340. PMID: 25002727.

22. Ronan SG, Eng AM, Briele HA, Shioura NN, Gupta TKD. Thin Malignant Melanomas With Regression and Metastases. Arch Dermatol. 1987;123(10):1326-1330. PMID: 3662564.

23. Tchernev G, Temelkova I. Primary Regressive, But Metastasizing Melanoma!? Open Access Maced J Med Sci. 2019;7(5):893-895. DOI: 10.3889/oamjms.2019.048. PMID: 30962857. PMCID: PMC6447344. 